\title{
PERANCANGAN APLIKASI RENCANA PEMBELAJARAN SEMESTER (RPS) UNTUK MENINGKATKAN PENCAPAIAN PEMBELAJARAN BAGI DOSEN
}

\author{
Gita Ayu Syafarina, M.Kom ${ }^{1)}$, Agus Setiawan, M. Kom ${ }^{2)}$ \\ ${ }^{\mathbf{1}}$ Fakultas Teknologi Informasi, Universitas Islam Kalimantan Muhammad Arsyad Al Banjari Banjarmasin \\ email : gitaayusyafarina@gmail.com \\ ${ }^{2}$ Fakultas Teknologi Informasi, Universitas Islam Kalimantan Muhammad Arsyad Al Banjari Banjarmasin \\ email : agusteknik08@gmail.com
}

\begin{abstract}
ABSTRAK
Rencana Pembelajaran Semester (RPS) adalah dokumen perencanaan pembelajaran yang disusun sebagai panduan bagi mahasiswa dalam melaksanakan kegiatan perkuliahan selama satu semester untuk mencapai capaian pembelajaran yang telah ditetapkan. Para dosen pengajar diwajibkan untuk membuat RPS sebelum kegiatan perkuliahan berlangsung. Objek sample penelitian untuk pembuatan sistem ini adalah Universitas Islam Kalimantan (UNISKA) Muhammad Arsyad Al Banjary adalah PTS tertua dan terbesar di Kalimantan Selatan khususnya untuk fakultas teknologi informasi yang notabene termasuk fakultas dengan dosen terbanyak. RPS pasti dikumpulkan oleh pihak fakultas sebagai berkas yang digunakan nanti pada saat akreditasi fakultas.Analisis sistem yang berjalan adalah pembuatan RPS masih menggunakan microsoft word, sehingga untuk point pengisian tiap variabel banyak berbeda antara satu sama lain. Seharusnya adanya sistem untuk mensamaratakan format pengisian otomatis, dan perekapan RPS. Berdasarkan permasalahan tersebut sistem yang akan dibuat akan memudahkan dosen untuk pengisian RPS yang benar maupun fakultas agar mudah dalam perekapan berkas RPS untuk keperluan akreditasi. Hasil analisis kebutuhan dengan menggunakan instrumen kuisioner kepada 15 orang responden, maka didapatkan hasil sebanyak $70 \%$ menyimpulkan perlu adanya pengembangan untuk sistem konvensional menjadi sistem yang terintegerasi. Hasil evaluasi akhir dari penggunaan sistem mendapatkan nilai presentase rata-rata $96 \%$ mendapatkan respon yang bagus sehingga layak untuk digunakan sebagai aplikasi RPS berbasis online.
\end{abstract}

Kata Kunci : Sistem, rencana, pembelajaran, semester, RPS, capaian, Dosen

\section{PENDAHULUAN}

Aplikasi perangkat lunak (bahasa Inggris: software application) adalah suatu subkelas perangkat lunak komputer yang memanfaatkan kemampuan komputer langsung untuk melakukan suatu tugas yang diinginkan pengguna.(https://id.wikipedia.org/wiki/Aplikas i diakses tgl 19 September 2018). Perancangan adalah penggambaran, perencanaan dan pembuatan sketsa atau pengaturan dari beberapa elemen yang terpisah ke dalam satu kesatuan yang utuh dan berfungsi Perancangan sistem dapat dirancang dalam bentuk bagan alir sistem (system flowchart), yang merupakan alat bentuk grafik yang dapat digunakan untuk menunjukan urutan-urutan proses dari sistem (Syifaun Nafisah, $2003: 2$ ).

Rencana Pembelajaran Semester (RPS) adalah dokumen perencanaan pembelajaran yang disusun sebagai panduan bagi mahasiswa dalam melaksanakan kegiatan perkuliahan selama satu semester untuk mencapai capaian pembelajaran yang telah ditetapkan. Para dosen pengajar diwajibkan untuk membuat RPS sebelum kegiatan perkuliahan berlangsung.

Objek sample penelitian untuk pembuatan sistem ini adalah Universitas Islam Kalimantan (UNISKA) Muhammad Arsyad Al Banjary adalah PTS tertua dan terbesar di Kalimantan Selatan khususnya untuk fakultas teknologi informasi yang notabene termasuk fakultas dengan dosen terbanyak. RPS pasti 
dikumpulkan oleh pihak fakultas sebagai berkas yang digunakan nanti pada saat akreditasi fakultas.

Analisis sistem yang berjalan adalah pembuatan RPS masih menggunakan microsoft word, sehingga untuk point pengisian tiap variabel banyak berbeda antara satu sama lain. Seharusnya adanya sistem untuk mensamaratakan format pengisian otomatis, dan perekapan RPS. Berdasarkan permasalahan tersebut sistem yang akan dibuat akan memudahkan dosen untuk pengisian RPS yang benar maupun fakultas agar mudah dalam perekapan berkas RPS untuk keperluan akreditasi.

\section{METODE PENELITIAN}

Metode yang digunakan pada penelitian ini adalah Case Studies, dan menggunakan tahapan daripada SDLC, yaitu seperti pada gambar dibawah ini:

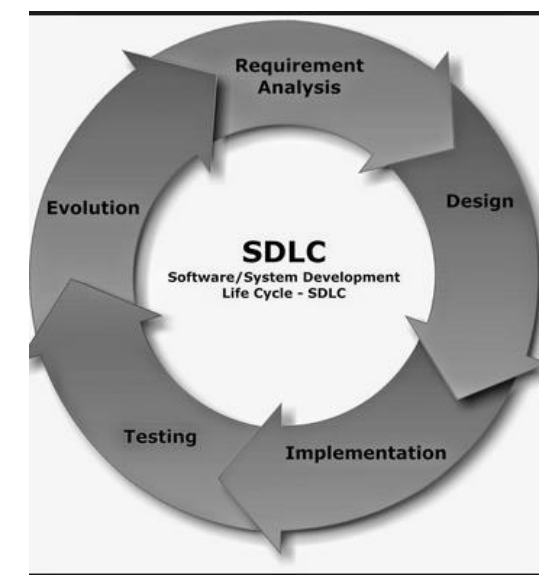

Gambar 1 Model SDLC

Berikut adalah tahapan daripada metode SDLC

1. Tahap analisis kebutuhan

2. Tahap desain sistem

3. Tahap implementasi

4. Tahap testing sistem

5. Tahap pengembangan

\section{HASIL DAN PEMBAHASAN}

a. Analisis Kebutuhan Instrumen yang digunakan pada tahap ini, yaitu : observasi dengan wawancara dan survey dengan memberkan kuisioner. Hasil survey dari 15 responden yaitu sebagai berikut :

Tabel 1 Kuisioner Analisa Kebutuhan

\begin{tabular}{|c|c|c|}
\hline Variabel & $\begin{array}{l}\text { Jumlah } \\
\text { Respon }\end{array}$ & Presentase \\
\hline $\begin{array}{l}\text { Kurang setuju } \\
\text { tentang sistem } \\
\text { konvensional } \\
\text { dalam pembuatan } \\
\text { RPS? }\end{array}$ & 8 orang & $53 \%$ \\
\hline $\begin{array}{l}\text { Kurang puas } \\
\text { dengan sistem } \\
\text { konvensional } \\
\text { dalam pembuatan } \\
\text { RPS }\end{array}$ & 7 orang & $47 \%$ \\
\hline $\begin{array}{l}\text { Tidak harus } \\
\text { menghilangkan } \\
\text { sistem } \\
\text { konvensional } \\
\end{array}$ & $\begin{array}{c}11 \\
\text { orang }\end{array}$ & $73 \%$ \\
\hline $\begin{array}{lr}\text { Sangat } & \text { perlu } \\
\text { suatu } & \text { aplikasi } \\
\text { untuk pembuatan } \\
\text { RPS }\end{array}$ & $\begin{array}{c}14 \\
\text { orang }\end{array}$ & $93 \%$ \\
\hline $\begin{array}{l}\text { sistem } \\
\text { konvensional } \\
\text { dalam harus } \\
\text { didampingi } \\
\text { dengan aplikasi } \\
\text { online } \\
\end{array}$ & $\begin{array}{c}13 \\
\text { orang }\end{array}$ & $86 \%$ \\
\hline
\end{tabular}

Berdasarkan hasil diatas rata-rata presentase di atas adalah $70 \%$ perlunya pengembangan daripada sistem konvensional 
b. Tahap Desain

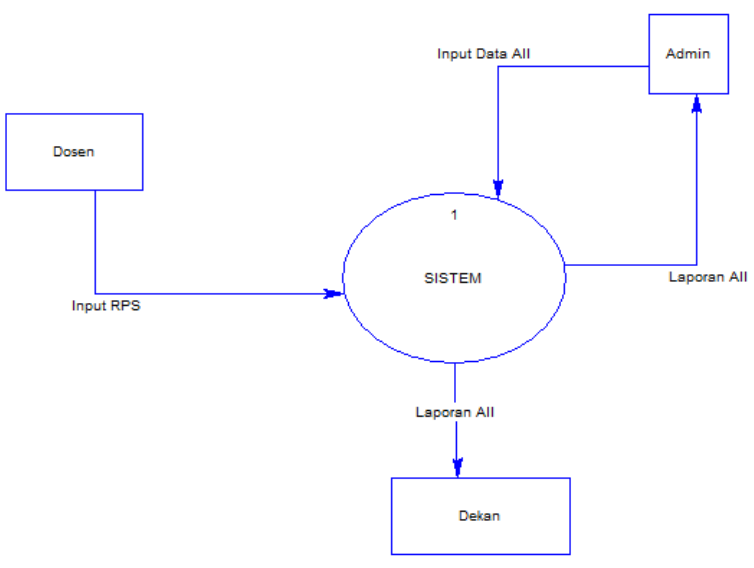

Gambar 2 Diagram Konteks

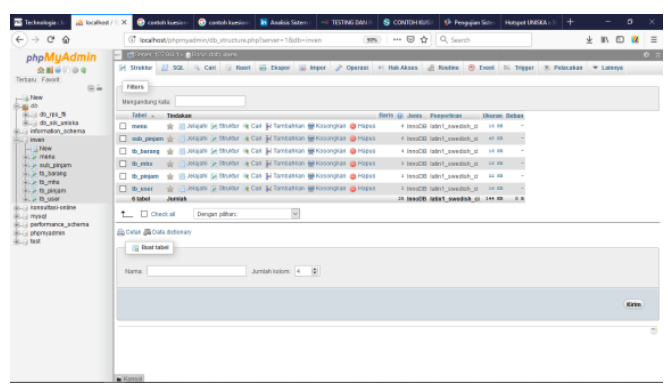

Gambar 3 Database

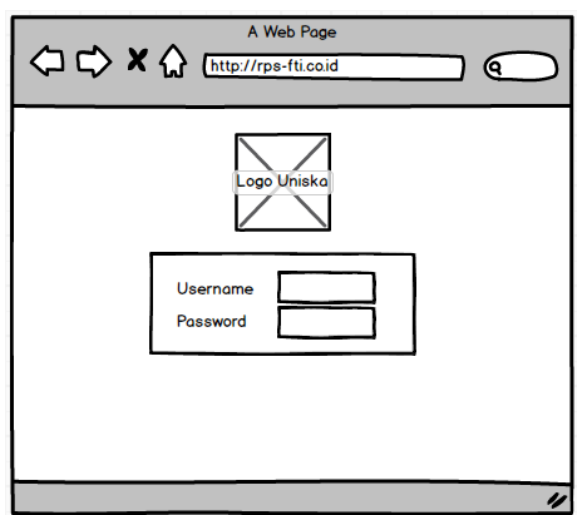

Gambar 4 Desain Mockup Login

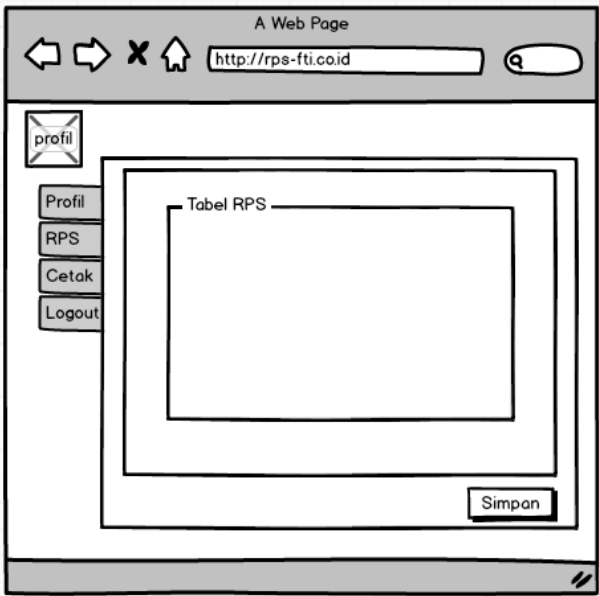

Gambar 5 Desain Mockup view RPS c. Tahap Implementasi

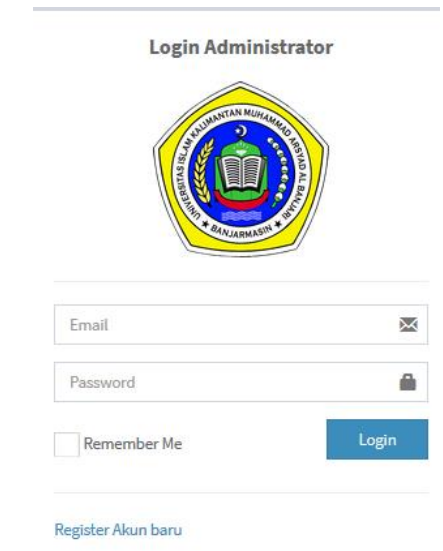

Gambar 6 Login Admin

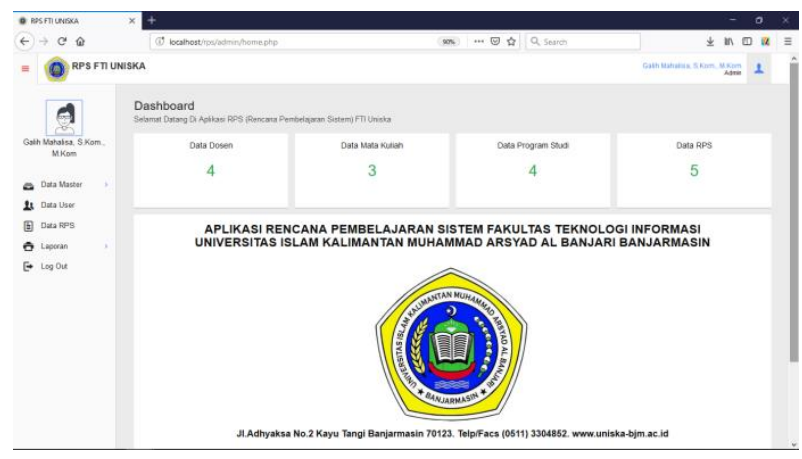


Gambar 7 Home Admin

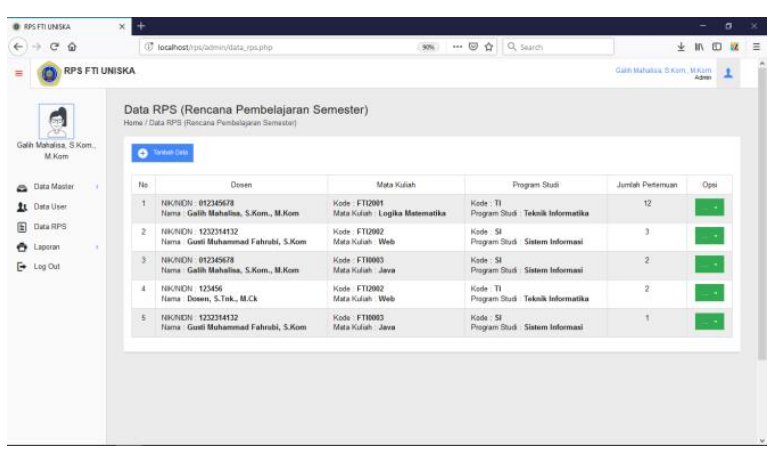

Gambar 8 View Data RPS

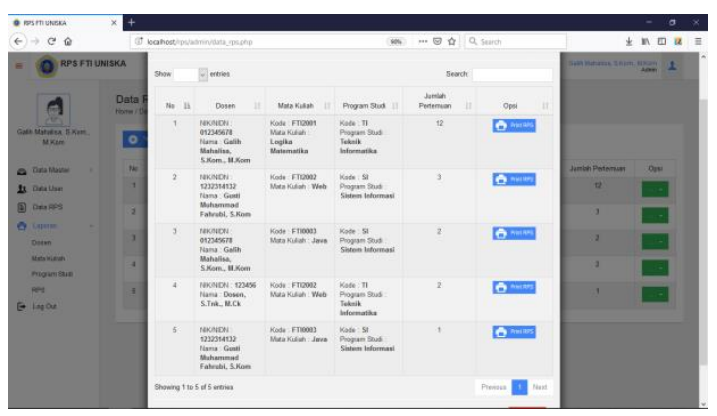

Gambar 9 Cetak RPS

Hasil evaluasi dari 15 responden setelah implementasi dan pengujian, yaitu sebagai berikut :

Tabel 2 Kuisioner Analisa Evaluasi

\begin{tabular}{|c|c|c|}
\hline Variabel & $\begin{array}{l}\text { Jumlah } \\
\text { Respon }\end{array}$ & Presentase \\
\hline $\begin{array}{lr}\text { Sangat } & \text { Puas } \\
\text { dengan } & \text { aplikasi } \\
\text { ini? } & \end{array}$ & $\begin{array}{c}15 \\
\text { orang }\end{array}$ & $100 \%$ \\
\hline $\begin{array}{ll}\text { Sangat } & \text { setuju } \\
\text { digunakan } & \text { untuk } \\
\text { RPS online } & \\
\end{array}$ & $\begin{array}{c}14 \\
\text { orang }\end{array}$ & $93 \%$ \\
\hline $\begin{array}{l}\text { Setuju untuk } \\
\text { mengurangi } \\
\text { sampah kertas }\end{array}$ & $\begin{array}{c}13 \\
\text { orang }\end{array}$ & $86 \%$ \\
\hline $\begin{array}{l}\text { Setuju } \\
\text { mengefisiensikan } \\
\text { waktu pembuatan }\end{array}$ & $\begin{array}{c}15 \\
\text { orang }\end{array}$ & $100 \%$ \\
\hline $\begin{array}{l}\text { sistem } \\
\text { konvensional }\end{array}$ & $\begin{array}{c}15 \\
\text { orang }\end{array}$ & $100 \%$ \\
\hline
\end{tabular}

\begin{tabular}{l}
\hline $\begin{array}{l}\text { harus didampingi } \\
\text { dengan aplikasi } \\
\text { online }\end{array}$ \\
\hline
\end{tabular}

Berdasarkan hasil diatas rata-rata presentasenya adalah $96 \%$ setuju dan puas setelah menggunakan aplikasi tersebut

\section{KESIMPULAN}

Kesimpulan yang didapatkan setelah melakukan implementasi dan beberapa pengujiian, maka dapat dipaparkan yaitu:

1. Hasil analisis kebutuhan dengan menggunakan instrumen kuisioner kepada 15 orang responden, maka didapatkan hasil sebanyak $70 \%$ menyimpulkan perlu adanya pengembangan untuk sistem konvensional menjadi sistem yang terintegerasi

2. Hasil evaluasi akhir dari penggunaan sistem mendapatkan nilai presentase rata-rata 96\% mendapatkan respon yang bagus sehingga layak untuk digunakan sebagai aplikasi RPS berbasis online.

\section{REFERENSI}

1] A. Kadir, "Pengenalan Sistem Informasi," Am. Enterp. Inst. Public Policy Res., 2014.

2] FN. Jovan, "Panduan Praktis Membuat WEB dengan PHP utk Pemula," MediaKita., 2014.

3] Mahalisa, G. (2018). PERANCANGAN SISTEM INFORMASI KAMPUS (SIK) BERBASIS WEBSITE STUDI KASUS KAMPUS UNISKA. SEMINASTIKA UNIVERSITAS MULIA BALIKPAPAN, 1(001), 101-103.

4] Agungsr, "Sistem informasi," Sist. Inf., 2011

5] E. Erni, "EVALUASI RENCANA PEMBELAJARAN IPS SD DAN UPAYA PERBAIKANNYA PADA MAHASISWA PGSD," Jurnal Teknologi Informasi Komunikasi Pendidikan. 2015. 
6] ARIF, Saiful Nur; WANDA, Ayu Putri; MASUDI, Abdi. Aplikasi Administrasi Perpustakaan Berbasis Web SMK Swasta Brigjend Katamso Medan. Jurnal SAINTIKOM Vol, 2013, 12.1.

7] M. P. Ismail, S.Pd. and STKIP Muhammadiyah Enrekang, "Rencana Pembelajaran Semester MK Bahasa Inggris PGSD," pbiummaspul, 2017. 